\title{
ECONOMIC AND ENVIRONMENTAL EFFICIENCY OF DISTRICT HEATING PLANTS
}

\author{
PER J. AGRELL AND PETER BOGETOFT
}

\begin{abstract}
District heating, the conversion of primary energy into distributed thermal energy and possible electric energy, is a challenge to regulate. In addition to the ever present asymmetric information in any sufficiently complex activity, some of the inputs for district heating, such as excess process heat, have arbitrary valuation. This study concerns the most developed European district heating and cogeneration system, the Danish. By assessing environmental and economic efficiency, the impact of governmental, market and managerial imperfections are estimated. The principal methodological base is the additive Data Envelopment Analysis model with extensions. The paper ends with some policy suggestions.
\end{abstract}

\section{INTRODUCTION}

The regulation of natural monopolies with high asset specificity is a complex task, in practice as well as in theory. Ever since the revival of regulatory economics in the early 1980s, the focus has been on the properties of the asymmetric information between regulator and regulated and its consequences on the firm's performance. Whatever angle is chosen, the transaction cost approach by Williamson (1976), the institutionalist approach by Demsetz (1969), the agency theory by Laffont and Tirole (1984) or the neo-classical Chadwickian approach by Klein and Leffler (1981), there is a intensified need for information and acknowledgement of the performances of the individual franchises. Systematic benchmarking through efficiency measurement is one method to ensure the accountability of the protected market operators. Two effects are obtained by such an exercise: First, the regulated firms are exposed to a quasi-competition, where the managerial efforts are gauged more than the actual economic realization. This information enables the firms to learn from successful technologies, routines and organizational forms. Second, the regulator and the captured clients are given yardstick norms, against which they may compare the performance of an individual firm. Related work (Bogetoft, 1994) on how to utilize the performance measures in actual incentive schemes may also be employed to create optimal regulatory regimes.

This paper reports on the efficiency of Danish heat plants and combined heat and power plants (CHPs) for district heating during 1998-2000. The CHP technology is inherently multidimensional, turning primary energy (process heat recovery, fossil fuels, biogas, pellets and other sources of energy) into both thermal and electric energy. The thermal energy, which anyway would result from the thermoelectric

\footnotetext{
Key words and phrases. DEA, benchmarking, district heating, regulation.

The authors are grateful for the generous support of the Danish Ministry of Energy and Environment and CORE, Université Catholique de Louvain, Belgium, during the 2000/2001 academic year.
} 
production, is utilized for district heating for subscribing customers. However, the process is characterized by losses due to process (conversion losses), heat transmission (transmission losses) and demand characteristics (balance losses). The managerial efforts are concentrated on the efficient conversion of primary fuels, depending on fluctuating prices and contractual agreements, to balance production. In terms of governance, there are publicly owned utilities (15\%), cooperative nonprofit utilities (84\%) and commercial energy providers (1\%). The non-commercial plants operate under cost-of-service regulation.

Primarily for environmental reasons, the Danish government subsidized the construction of cogeneration plants during the 1980s, even in small and medium scale applications. Several distortions were introduced to the cogeneration market. First, the fuel cost was initially skewed to favor domestic natural gas, causing a high number of small-scale gas plants to be installed. Second, to protect the incumbents against competing heating options, the incumbent plants were granted preemptive delivery and connection rights at their locations. Third, to counterbalance the latter action, the plants were put under a not-for-profit regime. Fourth, cogeneration plants were given exclusive rights to feed generated electricity to the local distributor at a preferential tariff, regardless of prevailing market price. The result was a strong increase in district heating and installation of decentralized heat plants. More than $50 \%$ of the non-industrial heat market was covered 1990 by district heating, considerably higher than in any comparable country, cf. Hendriks and Blok (1996). However, when opening parts of the fuel market for competition in accordance with EU-regulations, the economy of the cogeneration plants as well as of their captive customers have come to the government's attention. The construction of the district heat concession in combination with integrated production technology clearly opens for crossubsidization of the competitive activity at the expense of the captive consumers. As the accounting practice does not necessarily provide the regulator with an unambiguous allocation scheme for the quasi-rent on sunk investments, there is ample room to exploit market power in the current setup. A cost-efficiency assessment here serves an important role to gauge the extent to which informational rents are being extracted.

A simplistic implementation of cost-efficiency towards alternative technologies, however, would not yield feasible policy results. Thermal energy always is at disadvantage compared to hydroelectric generation, since the prior storage of the primary energy is attached with substantial costs, whereas hydroenergy has no holding costs. It is also of considerable policy relevance to distinguish between excess costs due to a legislative dead-weight, i.e., the technological lock-in in expensive fuel choices, and informational rents that are due to montioring costs and lack of effort by disincentivized managers, i.e., non-competitive acquisition of fuel, excessive transmission losses, or indirect extraction of rents through operating expenditure. A fair ex post analysis used as a part of an ex ante regime also needs to account for the prior uncertainty in prices on fuel and output that prevail. Further, from an operational viewpoint, there is little interest to benchmark against average performance, given that a large proportion of the plants are small and allegedly economically inefficient, which automatically would render the large-scale cogeneration plants suboptimal informational rents. Thus, the district heat industry in Denmark is well suited for the flexible production space description in Data Envelopment Analysis (DEA). 
Pricing the environmental effects on reduction of $\mathrm{CO}_{2}$ and other emission levels directly would imply certain arbitrariness and would not necessarily help to promote managerial efficiency. However, by using the flexible production frontier in DEA, estimates may be given on optimal production in the long and short run, without specifying the trade-off ratios. The approach has also the added managerial benefit of highlighting best practice, rather than average practice. In a non-competitive sector with motivation problems, average performance may be well in the interior of the production opportunity set.

Currently, there are some 450 district heating plants in Denmark, producing over 120,000 TJ of thermal energy and $2.3 \mathrm{TWh}$ of cogenerated electric power. The length of the distribution network is over $47,000 \mathrm{~km}$, supplying 1.4 million households (56\% of all households) in Denmark. Many of the plants are very small, $70 \%$ of the thermic heat is produced by $10 \%$ of the plants. The primary fuel technologies are varying between coal, oil, natural gas, straw, wood chips, and other bio fuel. The majority of the plants $(73 \%)$ distribute heat from cogeneration plants, but also industrial heat and heat from waste incineration are employed. The Danish Association of District Heating Utilities (DFF) organizes most of the producers (98\% of total heat volume, 410 members in 2000) and also publishes detailed statistics on the industry (answering frequency $79 \%$ of total plants, or $88 \%$ of total heat volume).

\section{Data Envelopment Analysis}

To formalize the above, we assume that each decision making units (DMU) in a comparable set, say $i \in G$, transform $m_{x}$ controllable inputs $x^{i}$ and $m_{z}$ noncontrollable categorical outputs $z^{i}$ into $m_{y}$ outputs $y^{i}$. The prices, if existing, on the controllable inputs and outputs are $w^{i} \in \mathbb{R}_{+}^{m_{x}}$ and $p^{i} \in \mathbb{R}_{+}^{m_{y}}$.

We assume that the technological possibilities are the same for all DMUs' (except for the differences captured by the non-controllable) variables. Specifically, these possibilities may be thought of as the set $T$ of feasible input -output combinations

$$
T=\{(x, z, y) \mid(x, z) \text { can produce } y\}
$$

We shall generally assume that $T$ satisfy

Condition 1. Free disposability: $(x, z, y) \in T, x^{\prime} \geq x, z^{\prime} \leq z, 0 \leq y^{\prime} \leq y \Longrightarrow$ $\left(x^{\prime}, z^{\prime}, y^{\prime}\right) \in T$.

Condition 2. Convexity: $T$ is convex.

Condition 3. $r$ returns to scale, $(x, z, y) \in T \Longrightarrow(q x, z, q y) \in T, \forall q \in \Gamma(r)$, where $r=$ "crs","drs," or "vrs", and $\Gamma($ crs $)=\Re_{0}, \Gamma(d r s)=[0,1]$ and $\Gamma($ vrs $)=\{1\}$, respectively.

Note that our definition of non-controllable variables implies a non-convex partitioning of the set $G$, such that the reference set for any DMU only contains units that individually face at least as difficult operating conditions. A radial inputoriented distance measure for the efficiency under $r$ returns to scale is defined by 
$\theta^{i}(r, G)$, the optimal solution to the program

$$
\begin{array}{ll}
\min _{\theta, \lambda} & \\
\text { s.t. } & x^{i} \theta \geq \sum_{k \in G} x^{k} \lambda^{k} \\
& z^{k} \lambda^{k} \geq z^{i} \lambda^{k} \\
& y^{i} \leq \sum_{k \in G} y^{k} \lambda^{k} \\
& \lambda \in \Gamma(r)
\end{array}
$$

where $\Gamma($ crs $)=\Re_{0}^{n}, \Gamma(d r s)=\left\{\lambda \in \Re_{0}^{n} \mid \sum_{i} \lambda^{i} \leq 1\right\}, \Gamma($ vrs $)=\left\{\lambda \in \Re_{0}^{n} \mid \sum_{i} \lambda^{i}=1\right\}$. The second constraint assures that DMU $i$ is only compared to convex combinations of DMUs, each of which have similar or worse conditions $z$, cf. Agrell and Tind (2001).

In this application, the so called additive model is also applied for primarily two reasons.

Firstly, the radial model is a rough instrument to assess inefficiency when $T$ is highly multidimensional and technologies frequently involve zero valued inputs. Although theoretically the slack variables would indicate residual slack for weakly efficient observations, the radial optimization problem is often difficult or impossible to solve under these degenerate conditions. The additive model is computationally superior to the radial and fully extremizes the slack variables to obtain strongly efficient comparators. Thus, it allows a greater flexibility in the trade-off between aggregation, possibly distorting the managerial discretion, and detail, threatening to impoverish the production model.

Secondly, the common disadvantages attached to the additive model, the lack of decomposition properties, sensitivity to scale and ambiguous interpretation, are addressed in this work. Below, we offer simple decomposition schemes based on exogenous prices to enable technological, cost and allocative efficiency measures. The scale sensitivity is irrelevant as so far as the unit of measurement in this application predominantly are commensurate, and elsewhere uniformly applied. Thanks to the decomposition and the modelling, the interpretation is unambiguous and clear.

Let the vector of input slacks be $s^{i}(r, G) \in R^{m_{x}}$ for unit $i$, obtained as the solution to the program

$$
\begin{array}{ll}
\max _{s, \lambda} & \sum_{h} s_{h}^{i} \\
\text { s.t. } & x^{i}-s \geq \sum_{k \in G} x^{k} \lambda^{k} \\
& z^{k} \lambda^{k} \geq z^{i} \lambda^{k} \\
& y^{i} \leq \sum_{k \in G} y^{k} \lambda^{k} \\
& \lambda \in \Gamma(r)
\end{array}
$$

A technical efficiency measure $T E^{i}$, analogous to the radial model $\theta^{i}$ above may be immediately calculated as

$$
T E^{i}(r, G)=1-\min _{h: x_{h}^{i}>0}\left\{\frac{s_{h}^{i}(r, G)}{x_{h}^{i}}\right\} .
$$


Thus, DMU $i$ is technically input-efficient iff $s_{h}^{i}=0$ for all inputs $h$, corresponding to the situation $\theta^{i}=1$ and all input constraints are binding. The formulation 2.2 differs from $\theta^{i}$ as it is done outside of the program, avoiding a potential scaling problem. Similarily, the scale efficiency $S E^{i}(G)$ for a DMU $i \in G$ may be defined using the standard definition from radial models as the ratio between the technical efficiency under constant returns to scale and technical efficiency under variable returns to scale.

$$
S E^{i}(G)=\frac{T E^{i}(\text { crs }, G)}{T E^{i}(\text { vrs }, G)}
$$

The cost-efficiency model $C E$ takes into account the average prices $w^{i}$ of inputs to assess the full economic implications of the chosen resource mix. Let $C^{i}=\sum_{h} w_{h} x_{h}^{i}$ be the total relevant cost for DMU $i$. The cost efficiency $C E^{i}(r, G)$ for DMU $i$ for a reference set $G$ under $r$ returns to scale assumption, given the resulting slack variables $s^{i}$ from the additive model, local prices and assuming $C^{i}>0$, will then be calculated as

$$
C E^{i}(r, G)=\frac{1}{C^{i}} \sum_{h} w_{h}^{i} s_{h}^{i}(r, G)
$$

However, we note that the solution to 2.3 need not be the correct in the case where the measuring units of $x$ implicitly give a skewed substitution rate in problem 2.1. As apposed to the radial model that is translation invariant, care should be exercised with the additive model to maintain the correct substitution rates. Here, we will initially make the restrictive assumption that $x$ is a vector of commensurate input units (e.g. input cost categories), such that 2.1 in itself yields a cost-efficiency measure.

Dynamic productivity evaluation is made with the Malmquist index. Assuming access to panel data for the years $t$ and $t+1$, we may calculate the dynamic efficiency changes by using the Malmquist index $M^{i}(t, t+1)$. Here, using the decomposition of Färe, Grosskopf and Lovell (1994), the relation between the frontier change $E F$ and the individual efficiency catch-up effect $E C$ is given by

$$
\begin{aligned}
M(t, t+1) & =\sqrt{\frac{T E^{t+1}\left(c r s, G^{t+1}\right) T E^{t}\left(\text { crs }, G^{t+1}\right)}{T E^{t+1}\left(c r s, G^{t}\right) T E^{t}\left(\operatorname{crs}, G^{t}\right)}} \\
& =\frac{T E^{t+1}\left(\operatorname{crs}, G^{t+1}\right)}{T E^{t}\left(\operatorname{crs}, G^{t}\right)} \sqrt{\frac{T E^{t}\left(c r s, G^{t+1}\right) T E^{t}\left(c r s, G^{t}\right)}{T E^{t+1}\left(c r s, G^{t+1}\right) T E^{t+1}\left(c r s, G^{t}\right)}} \\
& =E C(t, t+1) E F(t, t+1)
\end{aligned}
$$

where the superscript $i$ of the DMU has been suppressed for clarity.

\section{MOdels}

When modelling the district heating activity in an production efficiency model, attention has to be paid with respect to the controllable variables. As the demand for heat, given the strong delivery privileges, has very limited substitution, the elasticity is deemed high. For the purposes of this paper, the output of heat, electricity and heating capacity are judged exogenously given. The inputs for the activity are the asset base, the capital, the primary energy input, labour and other expenses. Two reasons speak against using capital in the current model. First, 
the valuation of capital that is available in the accounting data is based on historic and possibly distorted costs. There is evidence that depreciation practices in public and regulated utilities in no way mimic the true replacement cost, nor any plausible cost of capital. Rather, the depreciation has been made ad hoc for mainly fiscal motivations. Second, the capital base, in the short run operation perspective must be considered a sunk specific investment. It is from a myopic economic viewpoint irrelevant whether this stranded cost is covered directly through taxes, distributed on the captive customers, or deducted from the initial investors' equity, as long as the demand is not affected. In short, the question on how to allocate quasi-rents on sunk investments must be separated from the evaluation of the operations of the firm. Since part of the rationale for this evaluation is to pinpoint market distortions and non-economic operations, it is moreover likely that a considerable part of the investments may not be repeated.

Let us start with the long-term ideal perspective. Below, we suppress the superscript $k$ for plant $k=1, \ldots, n$. Recognizing that the Danish government's promotion of district heating rather than individual boilers has an environmental justification, we include the total carbondioxide $\left(\mathrm{CO}_{2}\right)$ emission as a controllable input, $x_{c o 2}$. This input has no given price and is calculated as the cascading $\mathrm{CO}_{2}$-emission in primary and secondary fuels. For secondary heat for which the source of energy is known, direct accounting has been used. For electricity, industrial heat and unspecified secondary energy sources, national average estimates have been used. In particular for electricity, the value used is the $\mathrm{CO}_{2}$ -emission per net GWh from power plants. The plant has a primary fuel vector $x^{p}=\left\{x_{\text {oil }}, x_{\text {coal }}, x_{\text {gas }}, x_{\text {wood }}, x_{\text {straw }}, x_{\text {biot }}, x_{\text {elec }}\right\}$ where $x_{\text {oil }}$ is the primary energy input from oil in TJ, $x_{\text {coal }}$ is the coal input in TJ, $x_{\text {gas }}$ is the natural gas input in TJ, $x_{\text {wood }}$ is the woodchips or pellets input in TJ, $x_{\text {straw }}$ is the straw input in TJ, $x_{\text {elec }}$ is the electrical energy consumed in MWh and $x_{\text {biot }}$ is the amount of primary input from other biofuels in TJ. The secondary heat vector $x^{s}=\left\{x_{c h p}, x_{i n d}, x_{i n c}, x_{\text {heatot }}\right\}$ consist of $x_{c h p}$, the purchased heat input in TJ from a generating plant, $x_{i n d}$ as the input of industrial heat in TJ, $x_{i n c}$ as the input (in TJ) of heat from waste incineration and $x_{\text {heatot }}$ as the secondary energy input (in TJ) of other heat. Cost data is also known as $c_{\text {opex }}$ for the total non-capital operating expenditures for operation, maintenance, administration and metering in millions of Danish crowns (MDKK), $c_{\text {heat }}$ which is the total cost for primary and secondary energy. The cost for primary energy may also be divided into components $c_{h}^{p}$, the primary fuel expenditure (in MDKK) for primary fuel $h=\{$ oil, coal, wood, straw, biot, elec $\}$. On the output side, we denote $y_{\text {heat }}$ as net delivered thermal energy in TJ, $y_{\text {elec }}$ as delivered electric energy in GWh, and $y_{\text {cust }}$ as the number of subscribed connection points of the distribution system. The revenue (in MDKK) generated from sales of electricity is denoted by $R_{\text {elec }}$. The length of the network $z_{\text {pipe }}$ (in $\mathrm{km}$ ) is here considered as a non-discretionary variable that serves as a proxy for capital intensity required. In the context of an output-oriented model, the inclusion of the network as an output would have been meaningless. Likewise, the inclusion of network as a controllable input would have been void in the absence of a proxy for the customer density.

To get a lower bound to the cost of service for heat, assume that the electrical output has no other value than a reduction of the cost of heat operations. Let the net non-capital cost be $C_{\text {netex }}=c_{\text {opex }}+c_{\text {heat }}-R_{\text {elec }}$ for each plant. We 


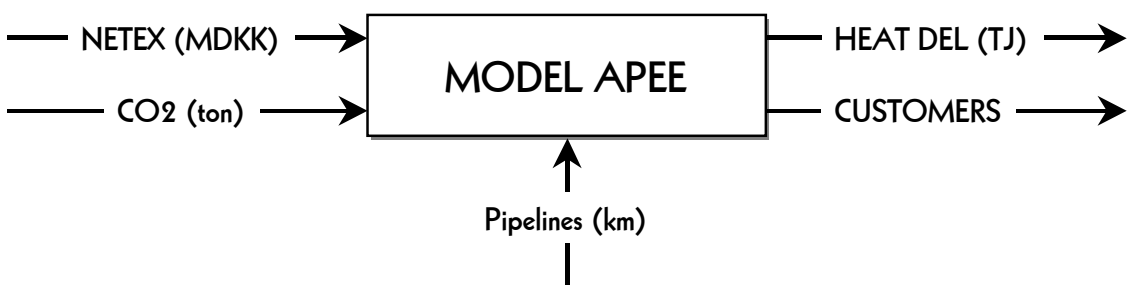

Figure 1. Activity model $A P E E$ with inputs and outputs.

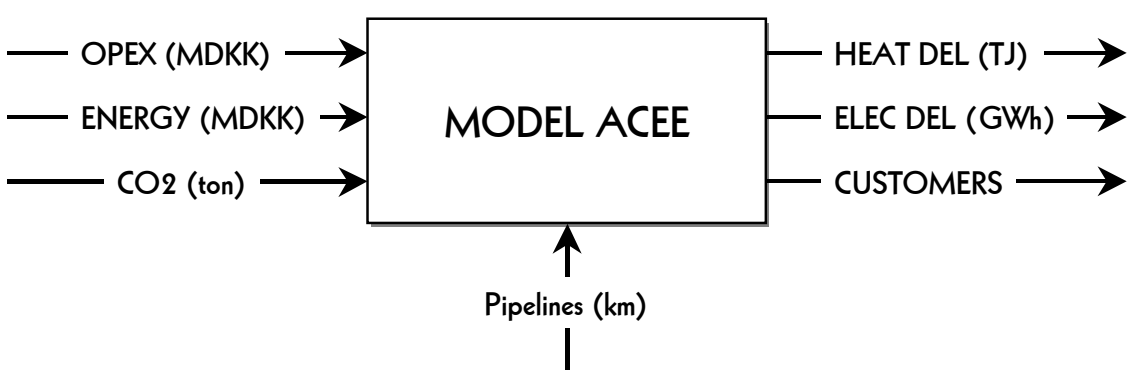

Figure 2. Production model $A C E E$ with inputs and outputs.

formulate the aggregated profit and environmental efficiency model $A P E E$ as the minimization of total net operating cost $C_{\text {netex }}$ and the $\mathrm{CO}_{2}$-emission $x_{c o 2}$ for each output vector $\left\{y_{\text {heat }}, y_{\text {cust }}\right\}$ given a network $z_{\text {pipe }}$.

The results from $A P E E$, illustrated in Figure 1, will by necessity be extreme and infeasible even in the long run, pointing at a major restructuring of the sector, change of technology, fuel providers and a further increase in the electricity production. As the preferential feed-in tariff is likely to be adjusted in the long run, the premium for change is overstated. In order to limit this influence from unknown electricity prices and to separate the fuel choice and fuel price effect, we formulate an aggregated cost and environmental efficiency model $A C E E$. In this model, Figure 2, the physical output electricity is measured in GWh and the non-capital cost is split in two inputs, $c_{\text {opex }}$ and $c_{\text {heat }}$.

To capture the regulator's long-run interest of the trade-off between environmental and economic efficiency, it may be of interest to make explicit the sector's cost of this added task. As a correction for $A C E E$, we formulate the aggregated cost efficiency model $A C E$ by deleting the environmental $x_{c o 2}$ as input, as in Figure 3 .

The models so far introduced cannot be applied to assess the managerial efficiency of the already existing plants. First, the heat volume possible is determined by the delivery area, which is pre-assigned. Second, the fuel choice is given by the installed technology, fixed in the short run. The current boilers are not to be changed prematurely, since the investment subsidies are scarce and likely to be withdrawn. In short, the aggregation on the input side makes assumptions about the discretionary ability on behalf of the plant manager that are not correct.

To assess operating efficiency, two models are introduced. The first, called the operational technical efficiency model OTE, considers the fuel input in physical terms 


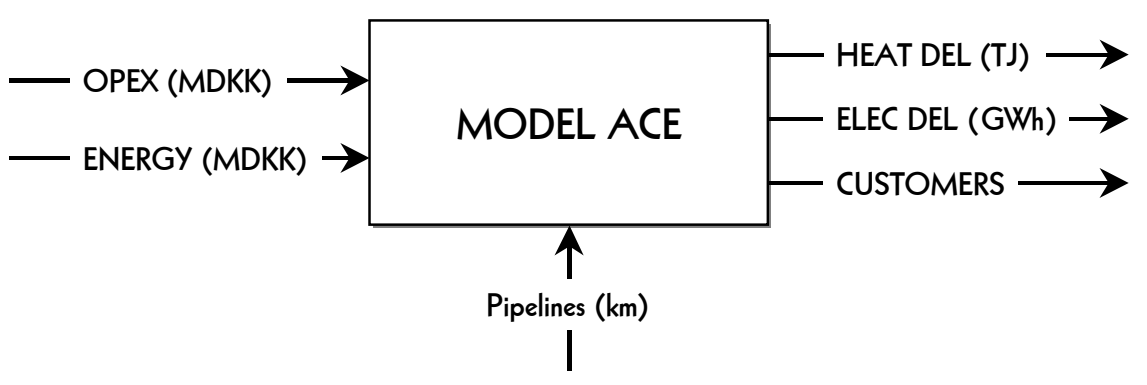

Figure 3. Production model $A C E$.

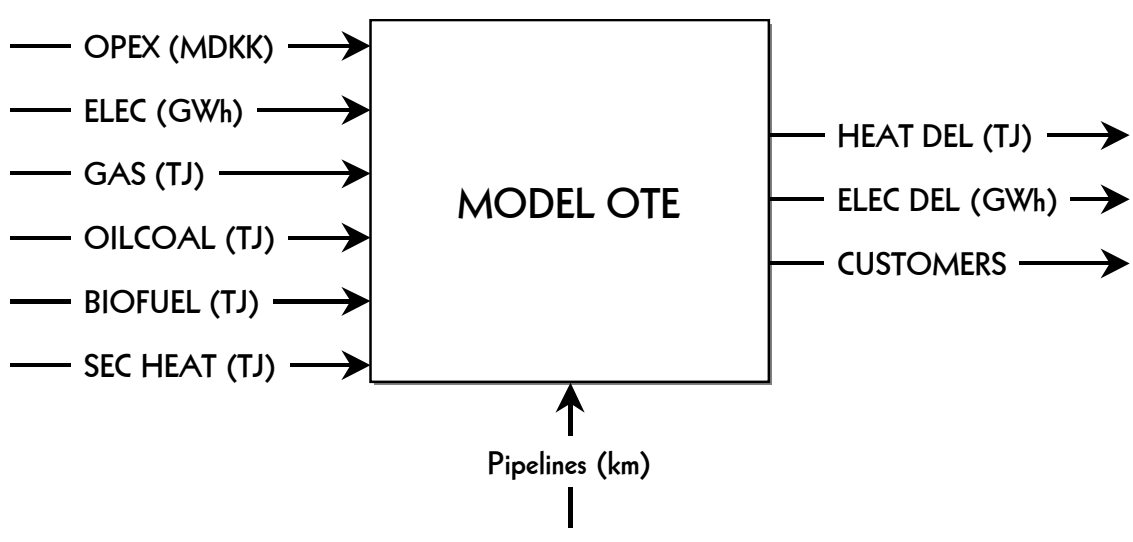

Figure 4. Production model OTE.

to be controllable within certain technologies, as well as operating expenditure in its entirety. The inputs are thus $x_{\text {opex }}, x_{\text {elec }}, x_{\text {gas }}$, and the aggregates $x_{\text {oilcoal }}=$ $x_{\text {oil }}+x_{\text {coal }}, x_{\text {bio }}=x_{\text {wood }}+x_{\text {straw }}+x_{\text {biot }}$ and $x_{s}=x_{c h p}+x_{i n d}+x_{\text {inc }}+x_{\text {heatot }}$. Further, as the energy sources correspond to given $\mathrm{CO}_{2}$-emission levels, the environmental input is redundant. Although this model also overstates the substitution possibilities between fuels and secondary heat sources, it does represent the most important plant technologies. The model is illustrated in Figure 4.

Finally, the operational cost efficiency model $O C E$ in Figure 5 captures the allocated budget to energy sources, as given by the available accounting data. Unfortunately, the data does not permit the calculation of reliable local prices of energy. Instead, we use the gross expenditures for the analogous groups as in model OTE (Figure 4$)$. Hence, the inputs are $c_{\text {opex }}, c_{\text {elec }}, c_{\text {gas }}, c_{\text {oilcoal }}, c_{b i o}, c_{s}$. The model is a disaggregated cost-efficiency model with all inputs in monetary terms (MDKK).

Due to numerical problems related to the size and sparsity of the matrix, the two latter models cannot be reliably solved using the radial model as above. Since the technology is easy to interpret and the inputs of model $O C E$ are measured in a common unit, the additive formulation lends itself as an easy solution.

In this particular context, market prices $w^{i}$ exist for all fuels but the predominant industrial heat, where prices are in part endogenously given as accounting production costs, given an arbitrary allocation of the fixed costs. However, since 


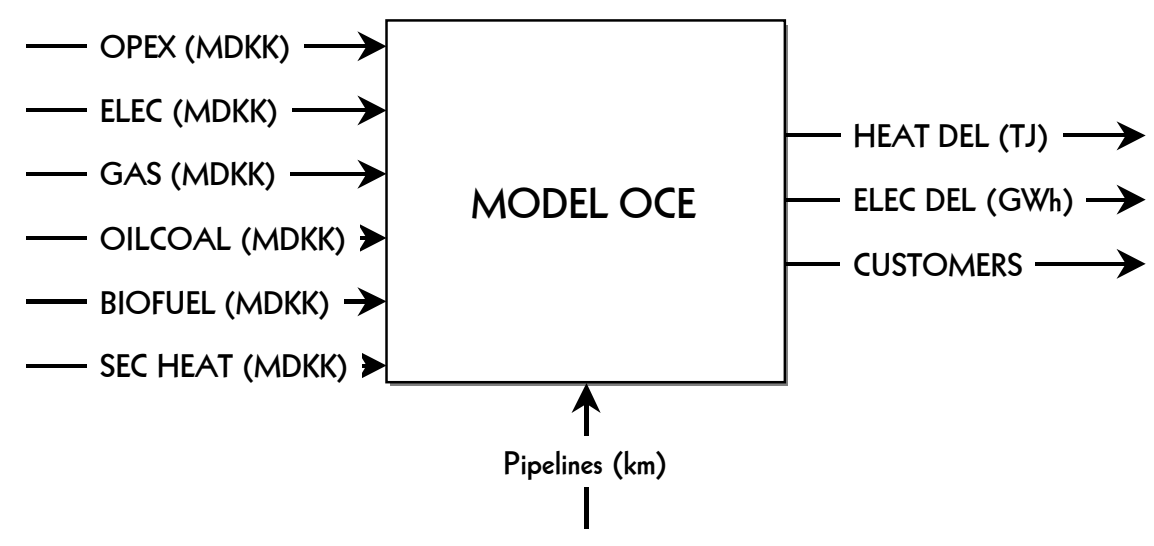

Figure 5. Production model $O C E$.

the purpose is to give a conservative estimate of the managerial efficiency, we choose to value the slack heat at the lowest of primary fuel prices, $w_{s}=\min _{h}\left\{w_{p h}\right\}$, which in this case corresponds to the price of biofuel (straw). Since all inputs of $O C E$ are nominated in MDKK, the valuation of $s_{\text {opex }}$ and all input slacks are set to 1 . Note that the obtained cost efficiency estimate for the additive model never will exceed a radial estimate, since all possible (non-proportional) input slacks are correctly valued. In this sense, the applied model gives both a more fair and more detailed description of the production set.

\section{DATA}

The data set includes 408 district heat plants in Denmark, divided into observations for the year 1998-99 and 1999-2000. Screening the data for omitted information and infeasibilities reduced the set to 310 observations 1998 and 253 observations 1999. In all 204 plants have valid and comparable data for both periods. In addition to the data directly utilized in the model, the set also includes technical data such as peak load, temperature levels feed-forward and return for Summer and Winter, total system water volume and the accounting costs for network, plants, operations, fuel, administration and net result. Tables 1 and 2 give a flavor of the descriptive statistics in the data set.

As given from Figure 6 and the apparent difference between mean and median values in Tables above, the majority of the Danish district heat plants are small and have sparse networks. In a sample of 285 plants with distribution network 1998, the 10 plants with the most dense network produce $43 \%$ of the total heat production. This immediately hints at the differences in underlying technology, where a large number of plants have mono-fuel technologies, low customer density and high-loss distribution networks. 
TABle 1. Descriptive statistics, district heating plants in Denmark 1998/1999.

\begin{tabular}{llrrrrrr}
\hline \hline & & Mean & Median & Min & Max & Standard.dev. & Sum \\
\hline$c_{\text {opex }}$ & $\mathrm{kkr}$ & 6,616 & 2,225 & 127 & 212,606 & 18,440 & $2,051,031$ \\
$c_{\text {heat }}$ & $\mathrm{kkr}$ & 19,116 & 6,003 & 429 & 646,777 & 56,387 & $5,925,813$ \\
$C_{\text {netex }}$ & $\mathrm{kkr}$ & 22,435 & 5,224 & $-6,304$ & 749,452 & 70,014 & $6,954,928$ \\
$x_{\text {co } 2}$ & $\mathrm{ton}$ & 490 & 118 & 0 & 19,010 & 1,825 & 151,993 \\
$z_{\text {pipes }}$ & $\mathrm{km}$ & 65 & 25 & 0 & 1,597 & 167 & 20,244 \\
$y_{\text {heat }}$ & $\mathrm{TJ}$ & 287 & 67 & 7 & 10,308 & 957 & 88,879 \\
$y_{\text {elec }}$ & $\mathrm{GWh}$ & 9 & 0 & 0 & 280 & 25 & 2,877 \\
$y_{\text {cust }}$ & $\#$ & 1,873 & 708 & 4 & 51,811 & 4,659 & 576,897 \\
\hline \hline
\end{tabular}

TABle 2. Descriptive statistics, district heating plants in Denmark 1999/2000.

\begin{tabular}{llrrrrrr}
\hline \hline & & Mean & Median & Min & Max & Standard.dev. & Sum \\
\hline$c_{\text {opex }}$ & $\mathrm{kkr}$ & 7,197 & 2,526 & 60 & 250,519 & 21,703 & $1,820,717$ \\
$c_{\text {heat }}$ & $\mathrm{kkr}$ & 21,385 & 7,278 & 82 & 750,690 & 63,133 & $5,410,389$ \\
$C_{\text {netex }}$ & $\mathrm{kkr}$ & 25,088 & 7,296 & 177 & 880,692 & 78,403 & $6,347,363$ \\
$x_{\text {co } 2}$ & $\mathrm{ton}$ & 484 & 125 & 0 & 27,287 & 2,007 & 122,503 \\
$z_{\text {pipes }}$ & $\mathrm{km}$ & 73 & 27 & 0 & 1,629 & 183 & 18,435 \\
$y_{\text {heat }}$ & $\mathrm{TJ}$ & 296 & 69 & 7 & 10,658 & 979 & 74,807 \\
$y_{\text {elec }}$ & $\mathrm{GWh}$ & 10 & 0 & 0 & 267 & 24 & 2,428 \\
$y_{\text {cust }}$ & $\#$ & 2,002 & 782 & 0 & 52,083 & 5,015 & 506,407 \\
\hline \hline
\end{tabular}

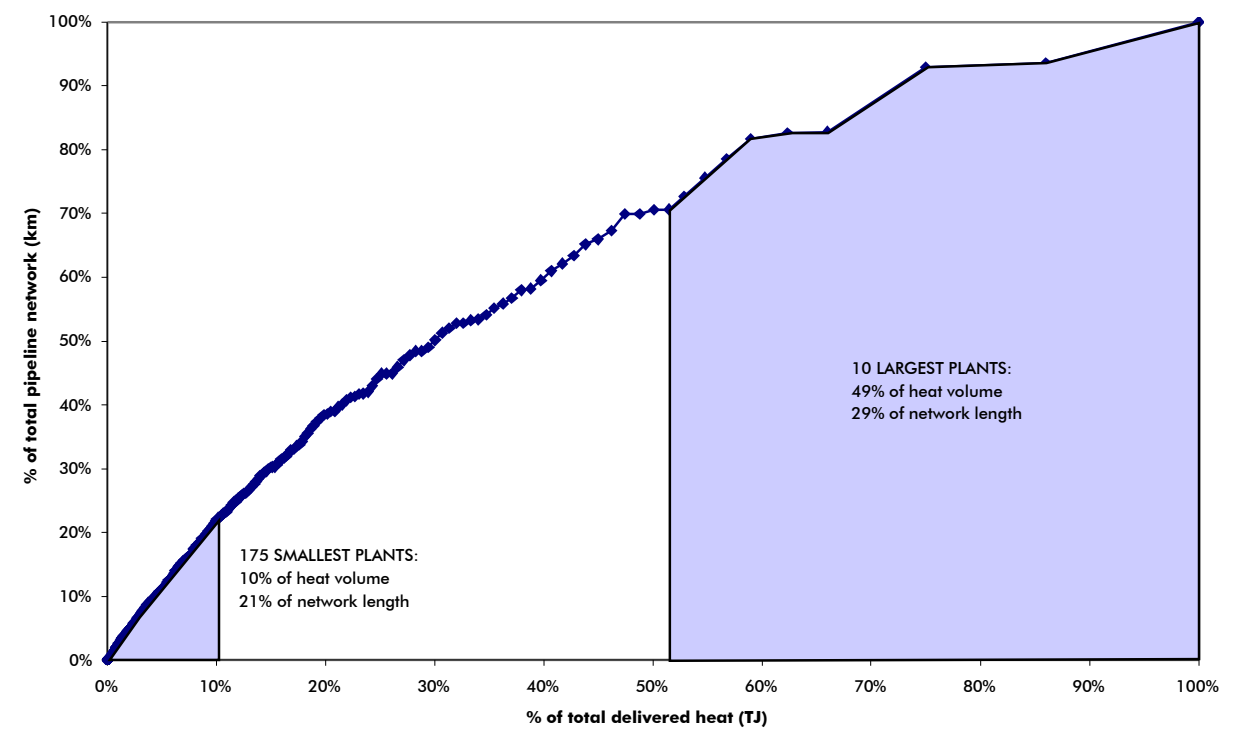

Figure 6. Proportion of total delivered heat volume (TJ) vs. proportion of pipeline network (km), 1998. 
TABLE 3. Efficiency results for 1998/99. N denotes the number of fully efficient DMUs.

\begin{tabular}{lrrrrrrr}
\hline \hline Model & $n$ & $N$ & Min & 1st q & Median & Mean & 3rd quart \\
\hline$A P E E($ crs $)$ & 307 & 5 & 0.15 & 0.30 & 0.37 & 0.43 & 0.51 \\
$A P E E($ vrs $)$ & 307 & 30 & 0.19 & 0.38 & 0.48 & 0.54 & 0.65 \\
$A C E($ crs $)$ & 310 & 17 & 0.25 & 0.50 & 0.59 & 0.62 & 0.70 \\
$A C E($ vrs $)$ & 310 & 36 & 0.26 & 0.55 & 0.64 & 0.68 & 0.81 \\
$O T E($ vrs $)$ & 310 & 157 & 0.24 & 0.85 & 1.00 & 0.91 & 1.00 \\
$O C E($ vrs $)$ & 310 & 151 & 0.36 & 0.79 & 0.97 & 0.88 & 1.00 \\
$A C E E($ crs $)$ & 310 & 32 & 0.28 & 0.54 & 0.65 & 0.68 & 0.82 \\
$A C E E($ drs $)$ & 310 & 51 & 0.28 & 0.56 & 0.67 & 0.70 & 0.86 \\
\hline \hline
\end{tabular}

TABLE 4. Efficiency results for 1999/2000. N denotes the number of fully efficient DMU.

\begin{tabular}{lrrrrrrr}
\hline \hline Model & $n$ & $N$ & Min & 1st q & Median & Mean & 3rd quart \\
\hline$A P E E($ crs $)$ & 253 & 4 & 0.11 & 0.28 & 0.39 & 0.40 & 0.48 \\
$A P E E($ vrs $)$ & 253 & 19 & 0.14 & 0.37 & 0.45 & 0.52 & 0.61 \\
$A C E($ crs $)$ & 253 & 14 & 0.21 & 0.52 & 0.62 & 0.63 & 0.72 \\
$A C E($ vrs $)$ & 253 & 26 & 0.24 & 0.56 & 0.68 & 0.69 & 0.80 \\
$O T E($ vrs $)$ & 253 & 107 & 0.13 & 0.84 & 0.94 & 0.89 & 1.00 \\
OCE $($ vrs $)$ & 253 & 132 & 0.23 & 0.76 & 1.00 & 0.87 & 1.00 \\
$A C E E($ crs $)$ & 253 & 20 & 0.21 & 0.54 & 0.65 & 0.67 & 0.78 \\
$A C E E($ drs $)$ & 253 & 35 & 0.21 & 0.56 & 0.67 & 0.70 & 0.84 \\
\hline \hline
\end{tabular}

TABLE 5. Total cost estimates for 1998-2000.

\begin{tabular}{lrrrrrrrr}
\hline \hline Year & \multicolumn{4}{c}{$1999 / 2000$} & & & \multicolumn{3}{c}{$1998 / 1999$} \\
\hline \hline$r$ & crs & vrs & $\widehat{c}_{\text {opex }}$ & $\widehat{c}_{\text {heat }}$ & crs & vrs & $\widehat{c}_{\text {opex }}$ & $\widehat{c}_{\text {heat }}$ \\
\hline$A P E E$ & 2,517 & 4,606 & - & - & 3,399 & 4,700 & - & - \\
$A C E$ & 3,702 & 4,691 & 1,418 & 4,156 & 4,366 & 5,237 & 1,574 & 4,547 \\
$A C E E$ & 4,054 & 5,020 & 1,504 & 4,400 & 4,802 & 5,560 & 1,651 & 4,792 \\
$O T E$ & - & 6,030 & 1,638 & 5,275 & - & 6,807 & 1,806 & 5,885 \\
OCE & - & 5,771 & 1,723 & 4,931 & - & 6,527 & 1,903 & 5,507 \\
Actual & 6,347 & 6,347 & 1,821 & 5,410 & 6,955 & 6,955 & 2,051 & 5,926 \\
\hline \hline
\end{tabular}

\section{RESUlts}

Some aggregated results from the domestic efficiency study are presented in Table 3 for the heatyears 1998/1999 and in Table 4 for 1999/2000. The efficient units exhibit the usual spread of technologies that may be expected in a non-parametric analysis under variable returns to scale. A convenient comparative table (Table 5) illustrates the findings as total cost estimates for the two years, divided into the cost categories operating expenditure and fuels, whenever possible. The estimated efficient inputs $h=\{$ opex, heat $\}$ for radial models (APEE, ACE, ACEE) are 
obtained as

$$
\widehat{c}_{h}=\sum_{k \in G} c_{h}^{k} \theta^{k}(r, G)
$$

and for additive models $(O T E, O C E)$ as

$$
\widehat{c}_{h}=\sum_{k \in G}\left(c_{h}^{k}-s_{h}^{k}(r, G)\right) .
$$

The last row of Table 5 gives the actual realized expenditure for the relevant sample. The rather high scale efficiency (e.g., for the $A C E$ model, $S E(98)=0.918$ and $S E(99)=0.914)$ does not provide evidence for any unexploited economies of scale. A more detailed subgrouping below reveals the central plants without distribution to more efficient, which in any case does not affect the ranking of the distributing plants.

The net-profit model $A P E E$ yields the predicted low scores for the industry in general. The few fully efficient plants are small distributors with heavy cogeneration, generating substantial contributions to the heat operations. To calculate the frontier three plants had to be removed from the 1998 sample, two of which had negative net expenditures, i.e., the heat consumer was debited only a part of the fixed cost and none of the variable. The increased heat demand in 1999/00 due to climate lowered the $A P E E$ efficiency for comparable observations. Cogeneration was utilized less intensively, fuel prices increased and the resulting average net expenditure per delivered heat energy rose from 74.8 DKK/GJ to 84.8 DKK/GJ. As an orientation for the regulator, the average efficient levels of net expenditure were 33.2 DKK/GJ ( APEE (crs, 98/99)) and 38.4 DKK/GJ ( APEE (crs, 99/00)), respectively. The average efficient levels under variable returns to scale were 42.4 DKK/GJ ( APEE (vrs, 98/99)) and 49.3 DKK/GJ ( APEE (vrs, 99/00)), respectively.

Turning to the aggregated cost efficiency measure $A C E$, the scores are still fairly low, with average inefficiencies of $31-38 \%$. Tables 3 and 4 display lower median than average scores, reflecting the fact that the minimum scores are very low. Compared to $A P E E$ the outcome of $A C E$ less favor the extreme cogenerators, allowing some pure heating plants to reach the efficient frontier. Still, the full substitutability assumption in the $c_{f u e l}$ input implies that the measure is purely for structural use. The $10 \%$ efficient plants in this world view ( ACE (vrs, 98/99)) produce $47 \%$ of the delivered heat using cost-efficient energy sources such as cogeneration heat, industrial process heat, waste incineration heat. The primary fuel conversion is atypical, only $2 \%$ of the total biofuels, $7 \%$ of the total natural gas and $7 \%$ of the oil fuel expenditure are passed through the efficient plants. Biofuels such as straw and woodchips, although competitively priced in other markets (Ek, 2000) do not make for cost efficient production in Denmark.

The environmental efficiency model $A C E E$ provides an immediate corrective for model $A C E$, with the addition of the net carbondioxide $\left(\mathrm{CO}_{2}\right)$ emission ${ }^{1}$. However, as cost efficient production in the sense of $A C E$ (primarily recovering cogeneration and process heat at favorable financial conditions) also is environmentally advantageous, the results largely coincide. Once again, the efficient plants are larger (15\% of the plants $1998 / 99$ deliver $50 \%$ of the total heat, $A C E E(d r s, 98 / 99)$ )

\footnotetext{
${ }^{1}$ An alternative model with three environmental inputs $\left(\mathrm{CO}_{2}, \mathrm{SO}_{2}, \mathrm{NO}_{x}\right)$ has been tested with results similar to $M 5$, which has been preferred as a simpler variant.
} 
TABLE 6. Productivity development results 1998-2000.

\begin{tabular}{lllrrrrr}
\hline \hline Model & $n$ & Min & 1st quart & Mean & Median & 3rd quart & Max \\
\hline$M(98,99)$ & 203 & 0.38 & 0.940 & 1.018 & 0.990 & 1.025 & 4.64 \\
$E C(98,99)$ & 203 & 0.73 & 0.891 & 0.952 & 0.940 & 1.005 & 1.23 \\
$E F(98,99)$ & 203 & 0.50 & 1.010 & 1.066 & 1.050 & 1.090 & 3.82 \\
\hline \hline
\end{tabular}

and have lower primary energy conversion (52\% of total secondary energy budget). Their carbondioxide emissions are about $47 \%$ lower per net energy delivered ( $A C E E(d r s, 98 / 99))$, much lower for $c r s$ results. A glance at Table 5 reveals that the total cost premium for this added environmental efficiency is moderate, some 6-7\% on top of the $A C E$ estimate, or about 300-350 MDKK annually. The cost increase due to inadequate scale, however, is $27 \%$ under low capacity utilization $(A C E E(d r s, 98 / 99))$ and $20 \%$ under higher heat volumes $(A C E E(d r s, 99 / 00))$. Size is not the only determinant, as evident in Figure 7. Clearly, the decentralized district heating comes at a premium, which only partially is offset by environmental benefits. Figure 8 gives another angle at the distribution of environmental efficiency, here graphed across the sum of operational and fuel expenditure.

Descending to the operational level with the disaggregated model OTE gives a brighter picture for the fuel management at the decentralized plants. Given fuel and distribution technology, about half of the plants are efficiently operated. Some interesting differences towards the structural measures are noticed. The efficient half of the plants delivers $85 \%$ of the total heat at lower operating and fuel costs (85.8 (87.4) DKK/GJ compared to 127.2 (140.3) DKK/GJ for 1998 and 1999, resp., OTE (vrs)) As opposed to the short-term competitive small cogenerators in $A P E E$, the best practice plants in $O T E$ are less involved in electricity distribution ( $45 \%$ and $46 \%$ of total electricity generation, 1998 and 1999 resp., OTE (vrs)) than their inefficient peers. The reasoning is sound and based on marginal generating costs compared to the fixed tariffs, although the marginal costs in this model is compared to average market prices. In terms of size, the average heat volume delivered of efficient plants is larger than average (436 and 575 TJ, OTE (vrs)), but considerably below the structural optimum (834 and 1,179 TJ for $A C E E(d r s)$ ).

Finally, the operational cost efficiency of model $O C E$ confirms at large the findings from its physical counterpart OTE. However, when actual rather than average prices are taken into account, the efficiency drops for inefficient fuel purchases. Savings in secondary energy sources, valued at $w_{\text {straw }}$ in $O T E$, may here be compared to the average cost for efficient plants of $43.1 \mathrm{DKK} / \mathrm{GJ}$ (OCE (vrs, 98/99)) and 45.2 DKK/GJ (OCE (vrs, 99/00)). This increases the estimated total cost as in Table 5 to some $23 \%$ (25\%) above the $A C E$ cost estimate, giving an estimate of the scope of market distortion costs, technology and managerial inefficiency. The potential managerial rent to be captured by regulatory action is thus limited to $9.1 \%(6.1 \%)$ of the total net operating expenditure, a fairly modest amount in the context.

The technological development of the industry (cf. Table 6) has been regressive during the period, measured using the $A C E E$ ( $c r s$ ) environmental efficiency model with the fuel input is physical terms [TJ]. Independent of the fuel price increases, the 


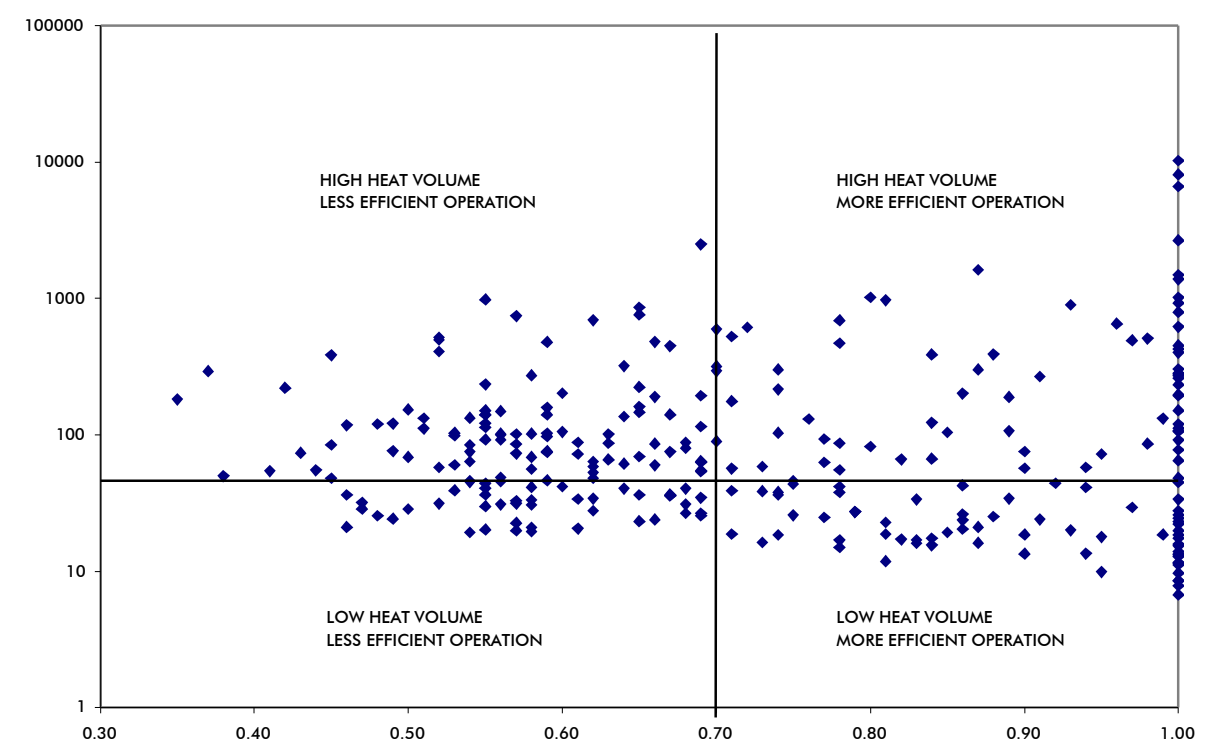

Figure 7. Costefficiency $A C E E$ under $r=d r s$ vs. heat delivered (TJ) 1998. Bold lines represent median values for efficiency and heat volume.

Malmquist index of productivity change increased by $1.8 \%$. The improvement is the residual effect of negative catch-up trend $(-4.8 \%)$ and a positive frontier movement. As argued above, the frontier change is propelled primarily by secondary energy sources, increased utilization of process heat, and continuing changes to non-fossil fuels. The negative catch-up effect deserves more detailed analysis of plant size, technology, ownership, etc., some of which is performed below.

Some dynamic results for subgroups are given in Table 7 , where $\mu_{j}$ denotes the mean and $\sigma_{j}$ the standard deviation for Group $j=\{1,2\}$. Beginning with the productivity development of the distributing $\left(z_{\text {pipe }}>0\right)$ vs. the nondistributing heat producers, the latter group analysis shows a strong regress in Malmquist productivity for the pure heat producers ( $-13.7 \%$ compared to distributors). Apart from a general efficiency fall-behind effect, shared among all plants, the heat plants also experienced a frontier digression in 1999/2000. Although further analysis is necessary to exactly determine the causes of this effect, the finding itself is important to refute the occasional intuition that correct scale is the only determinant in CHP efficiency.

Electricity cogenerators $\left(y_{\text {elec }}>0\right)$ have a significantly higher catch-up effect than non-electricity producers. Part of this effect comes from a somewhat slower productivity frontier change, the other probably due to closer to optimal size distribution among cogenerators.

Plants with natural gas fuelling $\left(x_{\text {gas }}>0\right)$ as well as plants without primary energy sources demonstrate less individual fall-back than other plants, for analogous reasons. The technological change seems very weak and the Malmquist index is close to 1. Albeit a comparatively expensive energy source, it offers a fairly reliable 
TABle 7. Dynamic efficiency analysis of subgroups (Group 2 consists of all plants not in Group 1). * denotes significant difference on the 0.975-level.

\begin{tabular}{llrrrrr}
\hline \hline Group 1 & Measure & $\mu_{1}$ & $\sigma_{1}$ & $\mu_{2}$ & $\sigma_{2}$ & $\mu_{1}-\mu_{2}$ \\
\hline$z_{\text {pipe }}>0$ & $M(98,99)$ & 1.026 & 0.30 & 0.889 & 0.21 & $0.137^{*}$ \\
$n_{1}=191, n_{2}=12$ & $E C(98,99)$ & 0.954 & 0.09 & 0.927 & 0.08 & + \\
& $E F(98,99)$ & 1.073 & 0.24 & 0.952 & 0.19 & $0.120^{*}$ \\
\hline$y_{\text {elec }}>0$ & $M(98,99)$ & 1.040 & 0.18 & 0.995 & 0.39 & + \\
$n_{1}=104, n_{2}=99$ & $E C(98,99)$ & 0.988 & 0.08 & 0.914 & 0.07 & $0.075^{*}$ \\
& $E F(98,99)$ & 1.053 & 0.16 & 1.079 & 0.30 & - \\
\hline$x_{\text {gas }}>0$ & $M(98,99)$ & 1.002 & 0.14 & 1.043 & 0.45 & - \\
$n_{1}=123, n_{2}=80$ & $E C(98,99)$ & 0.968 & 0.09 & 0.928 & 0.08 & $0.040^{*}$ \\
& $E F(98,99)$ & 1.036 & 0.12 & 1.112 & 0.34 & - \\
\hline$x_{\text {biot }}>0$ & $M(98,99)$ & 1.064 & 0.49 & 0.997 & 0.15 & + \\
$n_{1}=63, n_{2}=140$ & $E C(98,99)$ & 0.928 & 0.09 & 0.963 & 0.08 & $-0.035^{*}$ \\
& $E F(98,99)$ & 1.132 & 0.37 & 1.036 & 0.12 & $0.096^{*}$ \\
\hline$x_{s}>0.9 x_{\text {heat }}$ & $M(98,99)$ & 1.007 & 0.14 & 1.039 & 0.48 & - \\
$n_{1}=158, n_{2}=94$ & $E C(98,99)$ & 0.969 & 0.08 & 0.918 & 0.09 & $0.051^{*}$ \\
& $E F(98,99)$ & 1.040 & 0.12 & 1.115 & 0.37 & - \\
\hline \hline
\end{tabular}

TABLE 8. Technical efficiency results for subgroups (Group 2 consists of all plants not in Group 1).

\begin{tabular}{llrrrrr}
\hline \hline Group 1 & Measure & $\mu_{1}$ & $\sigma_{1}$ & $\mu_{2}$ & $\sigma_{2}$ & $\mu_{1}-\mu_{2}$ \\
\hline$z_{\text {pipe }}=0$ & OTE $($ vrs, 98$)$ & 0.90 & 0.12 & 0.96 & 0.08 & $-0.050^{*}$ \\
$n_{1}=34, n_{2}=292$ & OTE $($ vrs, 99$)$ & 0.88 & 0.16 & 0.93 & 0.11 & $-0.050^{*}$ \\
& APEE $($ crs, 98$)$ & 0.41 & 0.17 & 0.62 & 0.25 & $-0.212^{*}$ \\
& APEE $($ crs, 99$)$ & 0.41 & 0.17 & 0.33 & 0.13 & + \\
\hline org $=4$ & OTE $($ vrs, 98$)$ & 0.90 & 0.12 & 0.94 & 0.11 & $-0.039^{*}$ \\
$n_{1}=266, n_{2}=142$ & OTE $($ vrs, 99$)$ & 0.88 & 0.16 & 0.92 & 0.12 & $-0.038^{*}$ \\
\hline \hline
\end{tabular}

and stable technology with low efficiency variance. For the plants that rely on cogeneration or process heat $\left(x_{s}>0.9 x_{\text {heat }}\right)$, the activity may also be characterized as stable when prices are controlled for.

Contrary to the stationary gas plants, solid biofuels (woodchips, straw, peat, etc.) as primary energy sources $\left(x_{b i o t}>0\right)$ demonstrated rapid frontier changes, resulting in significantly lower catch-up scores. Varying prices and sources may have contributed to the instability, as well as an adverse selection in plant size and network density.

Dwelling at the issue of pure heat producers, Table 8 provides further details for the OTE (vrs) and APEE (crs) models. Beginning at the latter profit-oriented model, the central producers were apparently unable to take profit of overcapacity 98/99 for electricity production. Consequently, the distributors show significantly higher scores, only to fall below in 99/00 (not significant). From an operational 


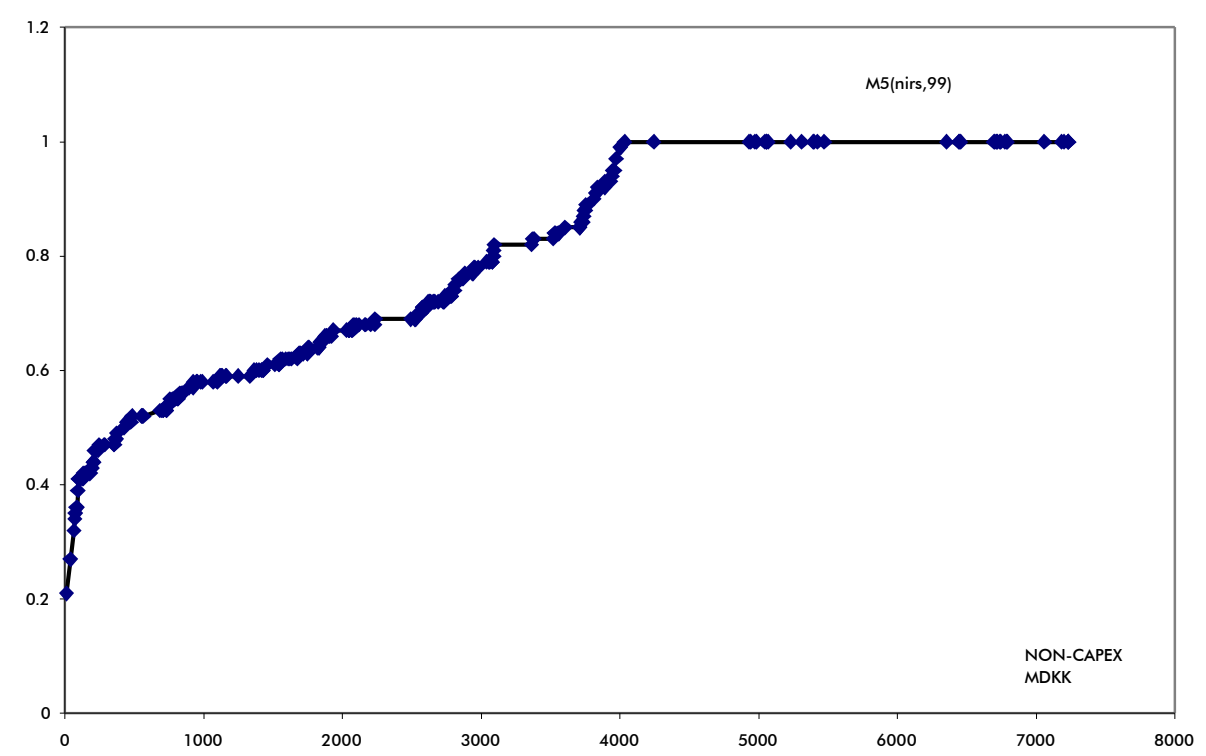

Figure 8. Aggregated cost and environmental efficiency $A C E E(d r s, 99)$ vs. $x_{\text {noncapex }, 99}$.

TABLE 9. Operational efficiency results for different technologies.

(Group 2 consists of all plants not in Group 1)

\begin{tabular}{llrrrrr}
\hline \hline Group 1 & Measure & $\mu_{1}$ & $\sigma_{1}$ & $\mu_{2}$ & $\sigma_{2}$ & $\mu_{1}-\mu_{2}$ \\
\hline$x_{\text {gas }}>0$ & OTE $($ vrs, 98$)$ & 0.91 & 0.10 & 0.90 & 0.15 & + \\
$n_{1}=183, n_{2}=143$ & OTE $($ vrs, 99$)$ & 0.90 & 0.12 & 0.86 & 0.20 & $0.044^{*}$ \\
& OCE $($ vrs, 98$)$ & 0.88 & 0.14 & 0.89 & 0.17 & - \\
& OCE $($ vrs, 99$)$ & 0.85 & 0.19 & 0.90 & 0.18 & -0.047 \\
\hline$x_{\text {biot }}>0$ & OTE $($ vrs, 98$)$ & 0.87 & 0.15 & 0.93 & 0.10 & $-0.053^{*}$ \\
$n_{1}=108, n_{2}=218$ & OTE $($ vrs, 99$)$ & 0.83 & 0.21 & 0.91 & 0.12 & $-0.084^{*}$ \\
\hline$x_{i n d}>0$ and $x_{\text {inc }}>0$ & OTE $($ vrs, 98$)$ & 0.99 & 0.03 & 0.90 & 0.12 & $0.087^{*}$ \\
$n_{1}=7, n_{2}=284$ & OTE $($ vrs, 99$)$ & 0.89 & 0.21 & 0.88 & 0.16 & - \\
& OCE $($ vrs, 98$)$ & 0.98 & 0.04 & 0.88 & 0.15 & $0.106^{*}$ \\
& OCE $($ vrs, 99$)$ & 0.98 & 0.05 & 0.86 & 0.18 & $0.118^{*}$ \\
\hline$c_{c h p}>0$ & OCE $($ vrs, 98$)$ & 0.83 & 0.21 & 0.90 & 0.12 & $-0.073^{*}$ \\
$n_{1}=94, n_{2}=232$ & OCE $($ vrs, 99$)$ & 0.77 & 0.26 & 0.91 & 0.13 & $-0.133^{*}$ \\
\hline \hline
\end{tabular}

perspective, the central plants exhibit lower scores, primarily in operating expenditure.

In passing, we note that ownership also has some influence. Cooperative distribution plants $($ org $=4)$ have significantly lower technical efficiency OTE (vrs) than private or publicly operated plants. Further analysis of the characteristics of this group is necessary to draw any conclusion regarding this aspect of the market structure. 
TABLE 10. Environmental efficiency results for technological subgroups (Group 2 consists of all plants not in Group 1).

\begin{tabular}{llrrrrr}
\hline \hline Group 1 & Measure & $\mu_{1}$ & $\sigma_{1}$ & $\mu_{2}$ & $\sigma_{2}$ & $\mu_{1}-\mu_{2}$ \\
\hline$c_{\text {coal }}>0$ & $A C E E($ vrs, 98$)$ & 0.58 & 0.18 & 0.68 & 0.181 & $-0.099^{*}$ \\
$n_{1}=25, n_{2}=301$ & $A C E E($ vrs, 99$)$ & 0.59 & 0.14 & 0.67 & 0.180 & $-0.083^{*}$ \\
\hline$x_{\text {biot }}>0$ & $A C E E($ vrs, 98$)$ & 0.60 & 0.17 & 0.71 & 0.18 & $-0.104^{*}$ \\
$n_{1}=108, n_{2}=218$ & $A C E E($ vrs, 99$)$ & 0.61 & 0.18 & 0.69 & 0.17 & $-0.077^{*}$ \\
\hline$c_{\text {oil }}>0$ and $c_{\text {coal }}>0$ & OCE $($ vrs, 98$)$ & 0.97 & 0.09 & 0.88 & 0.147 & $0.087^{*}$ \\
$n_{1}=18, n_{2}=197$ & OCE $($ vr, 99$)$ & 0.99 & 0.03 & 0.85 & 0.190 & $0.143^{*}$ \\
& $A C E E($ vrs, 98$)$ & 0.59 & 0.21 & 0.70 & 0.178 & $-0.104^{*}$ \\
& $A C E E($ vrs, 99$)$ & 0.59 & 0.17 & 0.68 & 0.167 & $-0.087^{*}$ \\
\hline$c_{\text {oil }}>0$ & OCE $($ vrs, 98$)$ & 0.83 & 0.21 & 0.90 & 0.12 & $-0.073^{*}$ \\
$n_{1}=94, n_{2}=232$ & OCE $($ vrs, 99$)$ & 0.77 & 0.26 & 0.91 & 0.13 & $-0.133^{*}$ \\
\hline \hline
\end{tabular}

Although the overall assessment of managerial inefficiency yields a fairly modest harvest, as above, there is still interest to investigate where the potentials may be the highest. Table 9 lists $O T E$ (vrs) and OCE (vrs) results for some selected groups of plants. First, the natural gas plants score higher in technical operations OTE $(v r s, 98)$ than other plants, but the cost efficiency is lower due to price increases $O C E(v r s, 99)$. Biofuel plants have considerably lower technical efficiency both years. Plants with both process heat and waste incineration heat recovery $\left(x_{i n d}>0\right.$ and $\left.x_{i n c}>0\right)$ scored highly in cost efficiency both years and in technical efficiency 1998, but falls back to the common technical efficiency level in 1999. Finally, plants purchasing secondary heat score increasingly lower than other plants in terms of cost efficiency. This is most probably due to the effect of a few very favorable heat purchase agreements that dominate in this part of the production set. Such outcome is also plausible since the price of heat recovery lacks an absolute comparator.

Table 10 gives some highlights from the environmental efficiency model $A C E E$ ( vrs). Less surprisingly, coal-fueled plants score consistently poorly in terms of $A C E E$ (vrs). More notable is the finding that biofueled plants in general score worse than other plants (including fossil-fueled). However, the economic arguments are evident in the comparison between cost efficiency $O C E(v r s)$ and environmental efficiency $A C E E$ (vrs) for plants with both oil and coal as primary fuels. The 18 plants concerned are among the most competitive in terms of cost, but are due to high emissions of carbondioxide environmentally inefficient. A similar finding can be stated for the numerous plants that use oil as fuel to some extent.

\section{Conclusion}

By careful modelling of the district heating sector in Denmark, we have been able to estimate the technical, environmental, cost-, and structural efficiency along with cost estimates. The sector is characterized by heavy governmental involvement both on the supply and demand side, by subsidies for investments, fuels, preferential feed-in tariffs and connection rights. When dismantling part of these distorting 
factors, the result is suboptimal operation, inefficiency. Considering the large range of realized costs per delivered heat unit, and in the light of recent discussion on informational rents and asymmetric information in the provision of regulated services, the public is inquiring whether the current situation is due to managerial influence.

In this paper, we argue that the impact of governmental action (plant size, fuel choice, network configuration) is likely to be in the magnitude of three times more important than managerial performance. Given a certain plant size, fuel technology and regulated side activities, the local plant manager has a limited discretion when it comes to the total variable cost. Since the average plant size is small and purchases are not coordinated, the plant acts as price taker on the national fuel market. Substitution between fuels is possible only for certain biofuel configurations, not all of which are economically viable on the Danish market. Costs for administration and maintenance of the plants are usually limited and under considerable pressure.

In summary, the current study does not immediately translate to a performance based incentive system for district heating. Before such system can be conceived, clear directions are necessary as to the question of residual claimants of regulatory capture. If the local consumers, the current owners of Europe's most widespread district heating system, shall bear the burden of changes in the regulation structure that render their investments worthless, there may be more than the boilers who are to be put under heat.

\section{REFERENCES}

[1] Agrell, P. J. and Tind, J. (2001) A Dual Approach to Nonconvex Frontier Models, Journal of Productivity Analysis, forthcoming.

[2] Balestieri, J. A. P., and P. De Barros Correia (1997) Multiobjective linear model for prefeasibility design of cogeneration systems, Energy, Volume 22(5), pp. 537-549

[3] Bogetoft, P. (1984) Incentive Efficient Production Frontiers: An Agency Perspective on DEA, Management Science, 40, pp.959-968.

[4] Chadwick, E. (1859), Results of Different Principles of Legislation in Europe, Journal of theRoyal Statistical Society, Series A22.

[5] Charnes, A., W.W. Cooper and E. Rhodes (1978) Measuring the Efficiency of Decision Making Units, European Journal of Operational Research, 2, pp. 429-444.

[6] Dismukes, D. E., and Kleit, A. N. (1999) Cogeneration and electric power industry restructuring, Resource and Energy Economics, 21(2), pp. 153-166.

[7] Demsetz, H. (1968), Why Regulate Utilities?, Journal of Law and Economics, Vol. 11.

[8] Ek, G. (2000) Swedish District Heating Efficiency. Report, Swedish National Energy Administration.

[9] Energistyrelsen (2000) Totalrådgivning til barmarkskraftværker. Commissioned report, COWI and Carl Bro.

[10] Gustavsson, L. (1997) Energy efficiency and competitiveness of biomass-based energy systems, Energy, Volume 22, Issue 10, pp. 959-967

[11] Hendriks, C. and Blok, K. (1996) Regulation for combined heat and power in the European Union, Energy Conversion and Management, 37, Issues 6-8, pp. 729-734

[12] Klein, B. and Leffler, K.-B. (1981) The Role of Market Forces in Assuring Contractual Performance, Journal-of-Political-Economy; 89(4), pp. 615-41.

[13] Laffont, Jean-Jacques and Tirole, Jean (1993), A Theory of Incentives in Procurement and Regulation. MIT Press.

[14] Olsen, O. J. and Munksgaard, J. (1998) Cogeneration and taxation in a liberalized Nordic power market, Utilities Policy, 7(1), pp. 23-33 
[15] Soares, J. B., Szklo, A. S., and Tolmasquim, M. T.(2001) Incentive policies for natural gasfired cogeneration in Brazil's industrial sector case studies: chemical plant and pulp mill, Energy Policy, 29(3), pp. 205-215

[16] Thompson, R. G., L. N. Langemeier, C.-H. Lee and R. M. Thrall (1990) The Role of Multiplier Bounds in Efficiency Analysis with Application to Kansas Farming. Journal of Econometrics, 46, 93-108.

[17] Tulkens, H. (1993) On FDH Efficiency Analysis: Some Methodological Issues and Applications to Retail Banking, Courts and Urban Transit, Journal of Productivity Analysis, 4, pp. $183-210$.

[18] Williamson, Oliver E. (1976), Franchise Bidding for Natural Monopolies: In General and with Respect to CATV, Bell Journal of Economics and Management Science, 7, 73-104.

iag School of Management, Center of operations research and econometrics (CORE), Université Catholique de Louvain, Voie du Roman Pays 34, B-1348 Louvain-la-Neuve, BELGIUM.

E-mail address: agrell@core.ucl.ac.be

Department of Economics and Natural Resources, Royal Agricultural University, Rolighedsvej 25, DK-1958 Frederiksberg C, DenMark

E-mail address: pb@kvl.dk 